\title{
NSTX High Temperature Sensor Systems
}

\author{
H. W. Kugela, B. McCormack ${ }^{\mathrm{a}}$, R. Kaita ${ }^{\mathrm{a}}$, P. Goranson ${ }^{\mathrm{b}}$, L. Guttadora ${ }^{\mathrm{a}}$, R. Hatchera, \\ T. Holoman ${ }^{\mathrm{a}}$, D. Johnson ${ }^{\mathrm{a}}$, B. Nelson ${ }^{\mathrm{b}}$, C. Neumeyer ${ }^{\mathrm{a}}$, and A. L. Roquemore ${ }^{\mathrm{a}}$

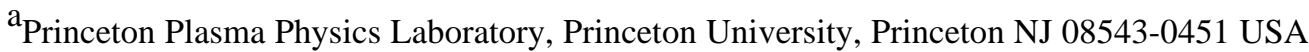

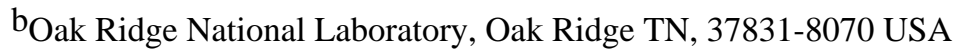

\begin{abstract}
The design of the more than 300 in-vessel sensor systems for the National Spherical Torus Experiment (NSTX) has encountered several challenging fusion reactor diagnostic issues involving high temperatures and space constraints. This has resulted in unique miniature, high temperature invessel sensor systems mounted in small spaces behind plasma facing armor tiles, and they are prototypical of possible high power reactor first-wall applications. In the Center Stack, Divertor, Passive Plate, and vessel wall regions, the small magnetic sensors, large magnetic sensors, flux loops, Rogowski Coils, thermocouples, and Langmuir Probes are qualified for $600{ }^{\circ} \mathrm{C}$ operation. This rating will accommodate both peak rear-face graphite tile temperatures during operations and the $350{ }^{\circ} \mathrm{C}$ bake-out conditions. Similar sensor systems including flux loops, on other vacuum vessel regions are qualified for $350{ }^{\circ} \mathrm{C}$ operation. Cabling from the sensors embedded in the graphite tiles follows narrow routes to exit the vessel. The detailed sensor design and installation methods of these diagnostic systems developed for high-powered ST operation are discussed.
\end{abstract}

\section{INTRODUCTION}

The National Spherical Torus Experiment (NSTX) has unique high temperature in-vessel sensor systems mounted in small spaces behind plasma facing armor tiles prototypical of possible high power reactor first-wall applications. NSTX is designed to investigate the physics of Spherical Tori (ST) in a device that can produce noninductively sustained high- $\beta$ discharges in the 1 MA regime and to explore approaches toward a small, economic, high power density Volume Neutron Source (VNS) and an ST reactor core.[1] Fig.1 shows a partial schematic cross section of the NSTX. The device capabilities include $\mathrm{R}=$ $0.85 \mathrm{~m}, \mathrm{a}=0.68 \mathrm{~m}, \mathrm{Ip}=1 \mathrm{MA}, \mathrm{B}_{\mathrm{T}}=0.3 \mathrm{~T}, \mathrm{k}=2.0, \mathrm{R} / \mathrm{a}=$ 1.27 and a $5 \mathrm{sec}$ maximum pulse length. The start-up will employ Ohmic Heating (OH), Electron Cyclotron Preionization (ECP), and Co-Axial Helicity Injection (CHI). Wall stabilization will be provided by close-fitting,

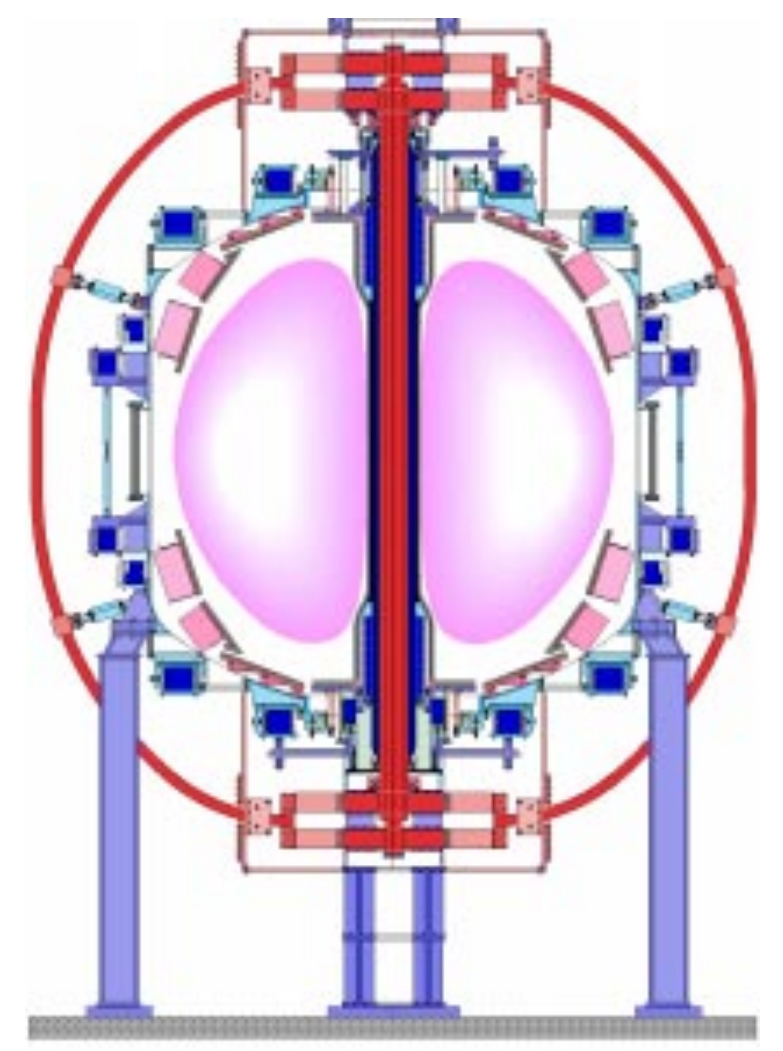

Fig.1. Partial schematic cross section of NSTX. The diameter of the Center Stack at the midplane is $38 \mathrm{~cm}$. The outer diameter of the vessel at the midplane is $341 \mathrm{~cm}$.

high conducting $2.5 \mathrm{~cm}$ thick copper Passive Stabilizer Plates. Auxiliary Heating will be provided by CHI, 6 MW of High Harmonic Fast Wave (HHFW) Radio Frequency heating, and 5 MW of Neutral beam Injection (NBI). Profile control will be studied using the HHFW, CHI, and NBI systems. The device has Divertors and allows for single-null, double null, and inner wall limited discharges. High power densities are expected on the Center Stack and Divertor. During high power, $5 \mathrm{sec}$ long discharges applied every $300 \mathrm{sec}$, e.g., the Center Stack tiles will receive incident power densities of $7 \mathrm{MW} / \mathrm{m}^{2}$ and reach peak front face temperatures of about $1200{ }^{\circ} \mathrm{C}$. The temper- 


\begin{tabular}{|c|c|c|c|}
\hline Location & Sensor & No. & $\begin{array}{c}\text { Install } \\
(\text { ed })\end{array}$ \\
\hline \multirow[t]{4}{*}{ CS-air } & Flux Loops & 17 & $2 / 15 / 99$ \\
\hline & Plasma Rogowski Coils & 2 & $2 / 15 / 99$ \\
\hline & Thermocouples & 24 & $2 / 15 / 99$ \\
\hline & Subtotal & 43 & \\
\hline \multirow[t]{6}{*}{ CS-vac } & Thermocouples & 32 & 6/1/99 \\
\hline & Langmuir probe & 14 & 6/1/99 \\
\hline & Bz Coils & 21 & 6/1/99 \\
\hline & 2D Coils & 12 & 6/1/99 \\
\hline & Halo Rogowski Coils & 4 & 6/1/99 \\
\hline & Subtotal & 83 & \\
\hline \multirow[t]{6}{*}{ Otr Div } & Flux Loop Tubes & 6 & 6/1/99 \\
\hline & Thermocouples & 20 & 6/1/99 \\
\hline & Langmuir probe & 10 & 6/1/99 \\
\hline & 2D Coils & 14 & 6/1/99 \\
\hline & Neutral Pressure Gauge & 1 & $2 / 99$ \\
\hline & Subtotal & 51 & \\
\hline \multirow[t]{7}{*}{ Sec PP } & Flux Loop Tubes & 8 & 6/1/99 \\
\hline & Thermocouples & 8 & $2 / 00$ \\
\hline & Langmuir probe & 0 & CY01 \\
\hline & 2D Coils & 12 & $2 / 00$ \\
\hline & Eddy Current Rog Coils & 8 & $2 / 00$ \\
\hline & Large 1D Coils & 12 & $2 / 00$ \\
\hline & Subtotal & 48 & \\
\hline \multirow[t]{8}{*}{ Pri PP } & Flux Loop Tubes & 8 & 6/1/99 \\
\hline & Thermocouples & 8 & $2 / 00$ \\
\hline & Langmuir probe & 0 & CY01 \\
\hline & 1D Coils & 8 & $2 / 00$ \\
\hline & 2D Coils & 16 & $2 / 00$ \\
\hline & Large 2D Coils & 12 & $2 / 00$ \\
\hline & Eddy Current Rog Coils & 8 & \begin{tabular}{|l|}
$6 / 1 / 99$ \\
\end{tabular} \\
\hline & Subtotal & 60 & \\
\hline \multirow[t]{4}{*}{ Otr In-Ves } & Flux Loop Tubes & 4 & 6/1/99 \\
\hline & Thermocouples & 12 & $2 / 00$ \\
\hline & Large 2D Coils & 18 & $2 / 00$ \\
\hline & Subtotal & 34 & \\
\hline \multirow[t]{4}{*}{ Ex-Vessel } & on Vessel Flux Loops & 12 & \begin{tabular}{|l|}
$8 / 1 / 99$ \\
\end{tabular} \\
\hline & on PF Coil Flux loops & 9 & \begin{tabular}{|l|}
$8 / 1 / 99$ \\
\end{tabular} \\
\hline & Subtotal & 21 & \\
\hline & Total & 340 & \\
\hline
\end{tabular}

Table 1. Vessel Sensor Summary. CS-air ( Center Stack Air-side), CS-vac (Center Stack,Vacuum-side), Otr Div (Outer Divertor), Sec PP (Secondary Passive Plates), Pri PP (Primary Passive Plates), Otr In-Ves (Outer Vessel interior Wall ), Ex-Vessel (Vessel air side).

-atures at the end of the cool-down after multiple pulses will be about $540{ }^{\circ} \mathrm{C}$. Analysis indicates that Divertor front face temperatures could exceed $1200^{\circ} \mathrm{C}$ design limit. Sweeping the strike-points could reduce the peak temperatures. Wall conditioning will be performed with Glow Discharge Cleaning, Bake-out to $350{ }^{\circ} \mathrm{C}$, and wall coatings. During Bake-out, the tiles will be maintained at $350{ }^{\circ} \mathrm{C}$, the view- ports and the signal cable feed through connectors and most of the vessel will be maintained at $150{ }^{\circ} \mathrm{C}$. The sensors mounted in the Center stack tiles are qualified for $600{ }^{\circ} \mathrm{C}$ operation. All other in-vessel tile sensors are qualified for $350^{\circ} \mathrm{C}$ Bake-out temperatures.

\section{OVERVIEW OF IN-VESSEL SENSORS}

Over 300 sensors either have been installed or are scheduled for installation inside the vacuum vessel or on outside of the vessel subject to bakeout temperatures. All sensor fabrication materials and signal cabling are qualified for $600{ }^{\circ} \mathrm{C}$ temperatures, and for operation in the NSTX vacuum chamber at base pressures in the $10^{-8}$ torr range. Table 1 gives a partial list of these sensors and their installation status. These include small 1-D Mirnov coils, small 2-D Mirnov coils, large 1-D Mirnov coils, interior Flux Loops, Halo current and Eddy current Rogowski coils, thermocouples, and Langmuir Probes. Outside the vacuum vessel, on the air-side of the Center Stack, are mounted Flux Loops, thermocouples and plasma current Rogowski coils. In addition, there are Flux Loops on the air-side of the vessel, and a Flux Loop mounted on each outer PF coil.

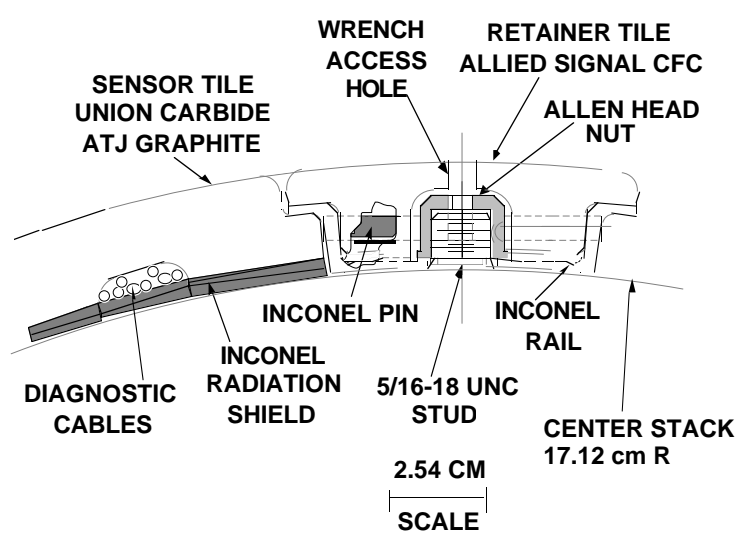

Fig.2. Partial schematic of $1.27 \mathrm{~cm}(0.5$ ") thick Center Stack Sensor Tile and Retainer Tile assemblies.

The design of the in-vessel sensor systems encountered the requirements of high temperatures, due to Bakeout and the expected thermal loads, as well as the small space available for embedding in the tiles, and in addition, the small spaces available for the exiting signal cables. The wall armor on the Center Stack consists of $1.27 \mathrm{~cm} \mathrm{(0.5")} \mathrm{thick} \mathrm{tiles}$ composed of alternating columns of Allied Signal C-C Composite tiles and Union Carbide ATJ graphite tiles fastened to the Inconel Center Stack with bolts (refer to Fig.2). All sensors on the Center Stack are embedded on the back-side of the $1.27 \mathrm{~cm}$ thick tiles and are separated from the Center stack by a $0.15 \mathrm{~cm}$ thick Inconel radiation shield. Each sensor tile has a $1.27 \mathrm{~cm}$ wide by $0.317 \mathrm{~cm}$ $\left(0.5^{\prime \prime} \times 0.125 "\right)$ deep vertical channel on the backside for the exiting signal cables. 


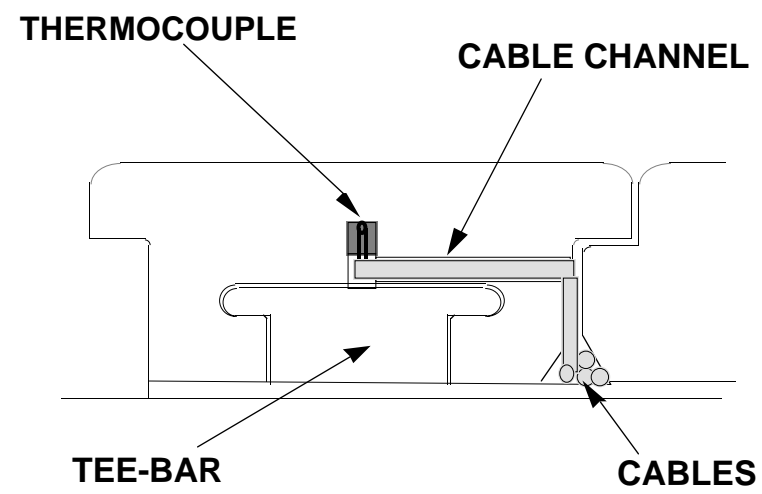

$1.27 \mathrm{CM}$

SCALE

Fig.3. Partial schematic of typical Divertor or Passive Plate graphite sensor tile design showing thermocouple.

The tiles cladding the Divertor and Passive Plate Stabilizer are $2.54 \mathrm{~cm}(1 ")$ thick Union Carbide ATJ graphite, and are mounted to the copper backing plate with Tee-bars with Grafoil, a thermal conductive gasket, between the tiles and the copper. All sensors cladding the Divertors and Passive Plates are embedded in the backside of the tiles mounted above the Tee-bars. These tiles are chamfered on the edge to allow an exit channel for the signal cables.

\section{SIGNAL CABLES}

The signal cables must be vacuum compatible with vessel base pressure in the low $10^{-8}$ torr range, qualified for $600{ }^{\circ} \mathrm{C}$ service (in the most severe case), and allow high quality transmission of low level signals in the presence of rapidly varying magnetic fields, and high electromagnetic interference. In principle, a twisted pair of conductors, insulated with a suitable silicon based fiber, and protected with a 304-SS braid can meet these requirements. However, the physics requirement to minimize the diameter of the Center Stack results in tiles of minimal thickness with very small cable exit channels $(1.27 \mathrm{~cm} \mathrm{x} 0.317 \mathrm{~cm})$ on the rear face of the tiles (Fig.2). This small exit channel must accommodate not only the signal cable exiting a particular tile but also signal cables from other tiles exiting via the same channel. This requirement eliminated typical commercially available 304-SS braided high temperature $\left(650^{\circ} \mathrm{C}\right)$ twisted pair wire. Thermo Electric Corp. Q-Glass insulated AWG No. 24 twisted non-jacketed copper-copper (Q/TW-24-) was selected for the sensor cable, and the Type$\mathrm{K}$ version (Q/TW-24-) for the thermocouple wire [2]. This is a twisted-pair, No. 24 gauge wire $(0.051 \mathrm{~cm} \mathrm{dia.})$ with a nominal outer width of about $0.2 \mathrm{~cm}$. This wire is typically available with a polyester silicone enamel saturant for color coding and providing mechanical stability during installation. In order to make the wire vacuum compatible at high temperature, it was air baked at $600{ }^{\circ} \mathrm{C}$ for 4 hours.
Testing of wire prepared in this manner for out-gassing in high vacuum at temperatures up to $600{ }^{\circ} \mathrm{C}$ using a Residual Gas Analyzer (RGA) indicated that it was suitable for operation in the NSTX environment. However, this procedure made the quartz-based jacket more fragile, and hence, after air-baking the wire was coated with a dilute mixture of boron nitride [3] and water. This was followed by an air bake at $125{ }^{\circ} \mathrm{C}$ for several hours to cure the coating, and after the final connection to the embedded sensor, a 4-6 hour $600{ }^{\circ} \mathrm{C}$ bake in a vacuum chamber whose base pressures reached the low $10^{-6}$ torr range by the end of the bake procedure. This coating of boron nitride provided protection to the glass fiber insulating jacket of the signal cable and increased its electrical insulating properties.

\section{Small 1D and 2D Mirnov Coils}

Miniature 1-dimensional (1-D) and 2-dimensional (2D) magnetic pickup coils ("Mirnov Coils") for sensing flux changes in one or two directions were fabricated for operating in the thin Center Stack tiles at $600{ }^{\circ} \mathrm{C}$. Ceramic coated wire [4], consisting of AWG No. 36 Kulgrid wire $(27 \% \mathrm{Ni} / \mathrm{Cu})$ and clad with a $0.013 \mathrm{~cm}(0.0005$ ") layer of

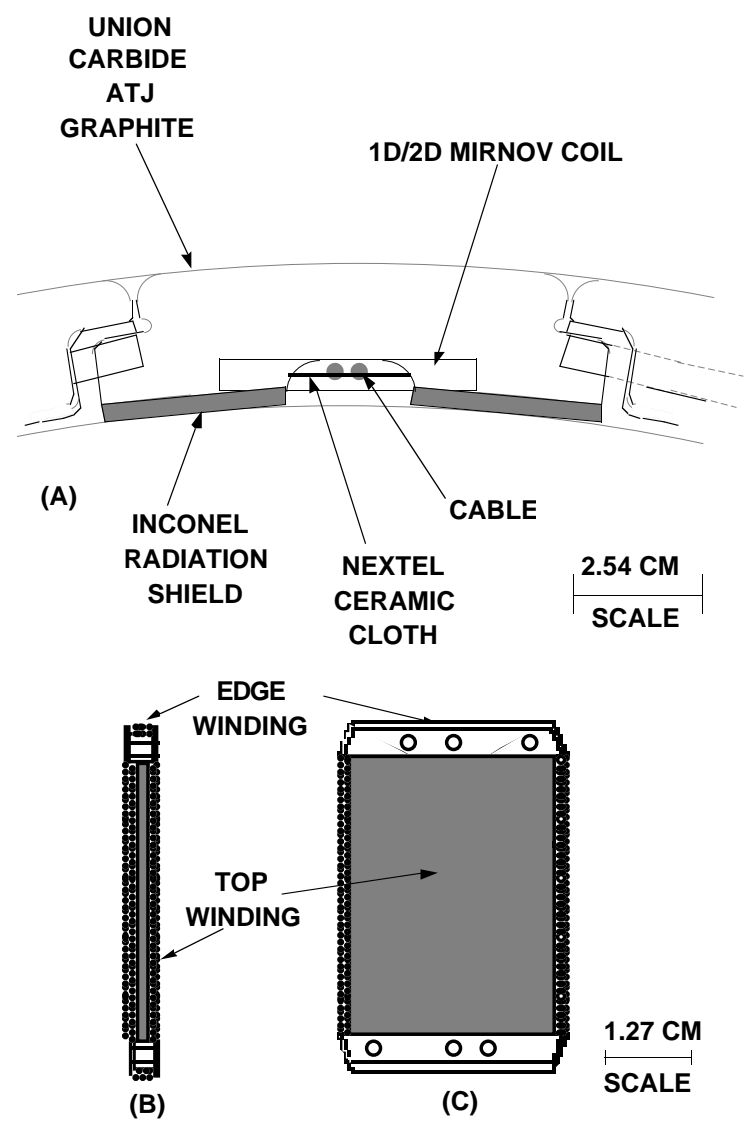

Fig.4. Partial schematic diagram of (a) miniature 1D/2D magnetic sensor coil (Mirnov Coil) installed in $1.27 \mathrm{~cm}(0.5$ ") thick Center Stack graphite tile, (b) edge view of 2D coil, (c) plasma facing view. of 2D coil 
ceramic was wound [5] on a MACOR [6] machineable glass ceramic coil form (see Fig.4). The same form was used for both $1 \mathrm{D}$ and $2 \mathrm{D}$ coils. The $1 \mathrm{D}$ winding coil consists of 2 layers No.36 ceramic coated wire with 190 turns per layer, and the 2D coils have an additional side winding of 2 layers with 14 turns per layer. The fabrication of the 2D Coils, for example, was particularly challenging due to the small space available for the exiting cables. Special fixtures identical in shape to the rear face of a Center Stack magnetic sensor tile were fabricated for the assembly procedure from commercially available casting material. Each fixture was first covered with a thin layer of standard flexible packaging material ("Saran Wrap"). Two twisted pair $\mathrm{Cu}-\mathrm{Cu}$ cables baked as described above (Sec. III) were untwisted and placed into the channel of the cast. An assembled 2D Coil was placed over the wires, and Omegabond-700 [7] ceramic adhesive was used to fix the wires and coil. The assembly was then removed from the coil form for welding of the No. $24 \mathrm{Cu}-\mathrm{Cu}$ wires to the No. 36 wire wound on the coil form. After welding, the coil with attached cables was placed into the recess machined in the rear-face of a Center Stack tile and bonded at 4 points with Omegabond-700 ceramic adhesive. Nextel ceramic cloth tape [8], $0.051 \mathrm{~cm}(0.020 ")$ thick was placed over the coil and bonded to the coil and wires with Omegabond700 ceramic adhesive [7]. In some instances, if the close tolerances did not permit the use of the Nextel cloth, then only a layer of Omegabond-700 was applied. The initial curing process was performed at room temperature. The final step in the curing process was an air bake at $200{ }^{\circ} \mathrm{C}$ for about 2 hours. The 2D Mirnov Coils for the thicker inner divertor tiles were fabricated in the same manner.

\section{Thermocouples}

Type-K, AWG No. 24, twisted pair, thermocouple wire [2] with $650{ }^{\circ} \mathrm{C}$ temperature rating was cut into units $3.7 \mathrm{~m}$ (12') long, stripped of insulation at one for a distance of $2.5 \mathrm{~cm}(1 ")$ and welded together to form a thermocouple junction about $0.102 \mathrm{~cm}(0.040 ")$ in diameter. After

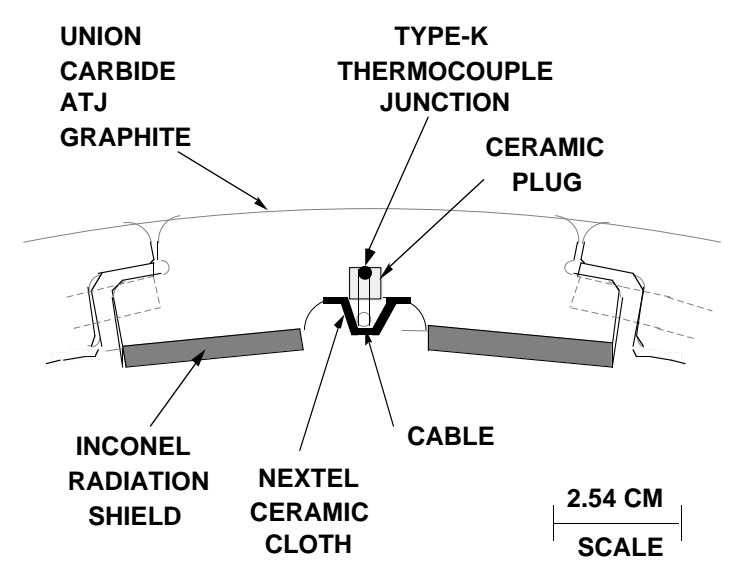

Fig.5. Partial schematic diagram of Type-K thermocouple mounted in $1.27 \mathrm{~cm}\left(0.5^{\prime \prime}\right)$ thick Center Stack graphite tile. welding, the thermocouple unit was air-baked, and then the junction was placed into a hole ("well") machined into the rear-face of a Center Stack tile. The thermocouple well is $0.318 \mathrm{~cm}(0.125 ")$ inside diameter by $0.318 \mathrm{~cm}(0.125 ")$ deep, which positioned the thermocouple junction 0.635 $\mathrm{cm}\left(0.25^{\prime \prime}\right)$ from the front face of the tile (Fig.5). A small bend radius was placed in the wire to allow for the $90^{\circ}$ transition from the well to the cable channel in a manner that provided a small spring tension to press the junction against the base of the well. Omegabond-700 [7], a high temperature ceramic cement was placed into the well to a height of about $50 \%$ of the well depth. This bonded the thermocouple into the well, and effectively created a molded ceramic plug in situ. Nextel ceramic cloth [8], $0.051 \mathrm{~cm}(0.020 ")$ thick by about 2.5-3.18 cm (1-1.3") long was cemented in the cable channel over the exiting thermocouple wires to press the junction into the well during the curing process, and to provide strain relief for the wires. The width of the Nextel cloth was dimensioned so that it followed the contours of the channel but did not protrude beyond the channel. A weight was placed over the Nextel and thermocouple wires during the curing process at room temperature. The final step in the curing process was an air bake at $200{ }^{\circ} \mathrm{C}$ for about 2 hours. The thermocouples for the thicker inner and outer divertor tiles were fabricated in the same manner.

\section{Langmuir Probes}

Small plasma probes (Langmuir Probes) were designed to be mounted flush to the front face of selected Center Stack and Divertor tiles. Each Langmuir Probe consists of a $2 \mathrm{~mm}$ diameter ATJ graphite probe tip insulated from the surrounding graphite tile by alumina insulators (Fig.6). Two twisted pair $\mathrm{Cu}-\mathrm{Cu}$ cables baked as described above

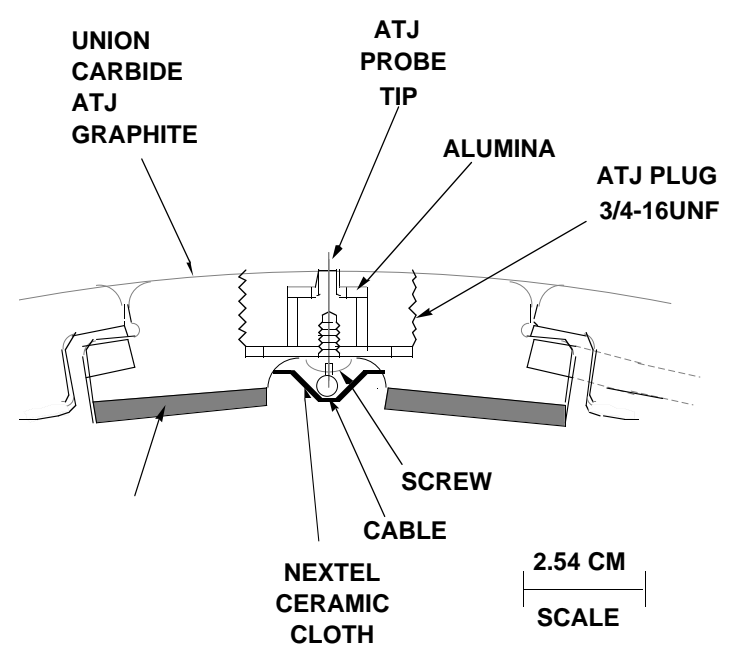

Fig. 6. Partial schematic of a diagram of flush mounted Langmuir Probe in $1.27 \mathrm{~cm}\left(0.5^{\prime \prime}\right)$ thick Center Stack graphite tile. 
(Sec. III) were welded to a head of a small screw. Thus, the screw head is connected to two wires for redundancy. The screw with the attached twisted pair cable was inserted into the probe tip, and the cable placed into the cable channel. A small amount of Omegabond-700 was placed over the welded junction of the cable and screw for strain relief. As in the case of the thermocouple assembly described above, Nextel ceramic cloth [8], $0.051 \mathrm{~cm}(0.020 ")$ thick by about 2.5-3.18 cm (1-1.3") long was cemented in the cable channel over the exiting Langmuir Probe wires to provide strain relief for the wires. The width of the Nextel cloth was dimensioned so that it followed the contours of the channel but did not protrude beyond the channel. A weight was placed over the Nextel and exiting wires during the curing process at room temperature. The final step in the curing process was an air bake at $200{ }^{\circ} \mathrm{C}$ for about 2 hours. The Langmuir Probes for the thicker inner divertor tiles were fabricated in the same manner.

\section{Large 1D Mirnov Coils}

There is a Passive Plate section between each of 12 bays (Fig.1). Each section is separated by a $5.08 \mathrm{~cm}$ (2") gap. A poloidal array of large 1-dimensional (1D) magnetic sensors ("Mirnov Coils") was mounted in this gap at one toroidal location. These Large 1D Mirnov Coils consist of two layers of 55 turns each, of AWG No. 26 ceramic wire [4] wound a MACOR [6] mandrel. The outside dimensions of the mandrel are $4.495 \mathrm{~cm} \times 3.493 \mathrm{~cm} \mathrm{x} 1.270 \mathrm{~cm}$ $\left(1.770 " \mathrm{x} 1.375^{\prime \prime} \times 0.5^{\prime \prime}\right)$. The ceramic wire is covered Nextel-312, $2.54 \mathrm{~cm}$ (1") wide ceramic tape [8] bonded to the coil with Fortafix Fiborclad high temperature adhesive cement [10] and secured with $0.051 \mathrm{~cm}(0.020$ ") ceramic thread [11]. Fig.7c show the details of the termination procedure for connecting the coil wire to the exit cables. The cables were clad with fiberglass sleeving [9] for the path to the electrical feedthroughs.

\section{Rogowski Coils}

Rogowski Coils are mounted around a conducting medium and measure the enclosed current. Inside the NSTX vessel, 4 Rogowski Coils are mounted around the Center Stack to measure plasma induced halo currents in the Center Stack. In addition, at present, 5 Rogowski Coils are mounted to measure the eddy currents induced in the lower Passive Plate supports. These are mounted so as to provide a toroidal array and a poloidal array at one lower vessel toroidal location. Eventually, depending on work in progress, there may be a total of 16 Rogowski Coils, a set of 4 coils, one on each Passive Plate element, at 4 toroidal locations. The in-vessel Rogowski Coils required special development in order to accommodate the required bend radii, small space limitations using relatively inflexible ceramic materials. A

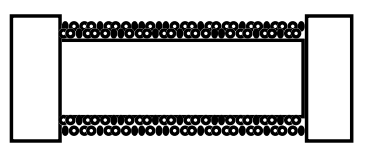

(A)
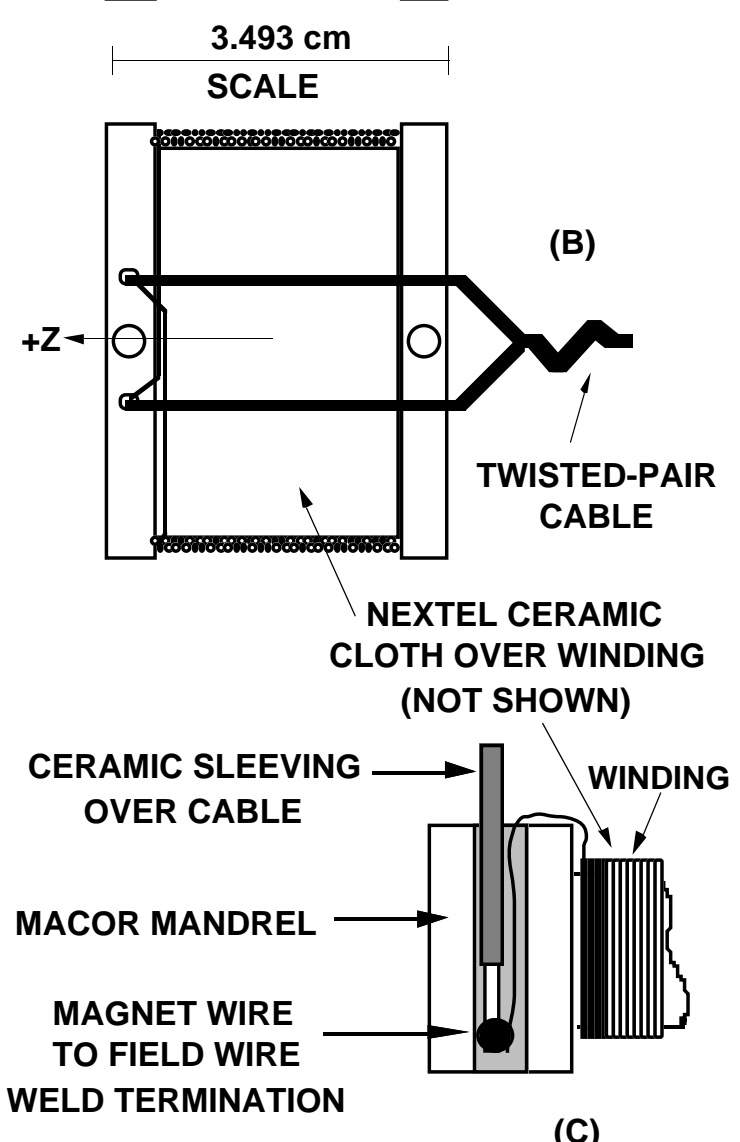

Fig.7. Partial schematic diagram of Large 1D Mirnov Coil magnetic sensors, (a) end view, (b) plasma facing view, (c) expanded detail of winding connection to cabling.

detailed description of this design is given in an associated paper in these Proceedings [12].

\section{Toroidal Flux Loops}

Flux Loops were installed on the air-side of the Center Stack (Table 1). These consisted of Teflon insulated AWG No. 22 copper wire $\left(220^{\circ} \mathrm{C}\right.$ rated) cemented in place with Omegabond-700 [7]. Inside the vessel (Fig.1 ), there are Flux Loops mounted under the upper and lower divertors, behind the copper Passive Plates, and on the inner outer wall . These Flux Loops consist of the same $\mathrm{Cu}-\mathrm{Cu}$ twisted pair wire described above and were baked in the same manner (Sec. III). This twisted pair wire was inserted into thin wall $0.025 \mathrm{~cm}\left(0.010^{\prime \prime}\right), 304-S S$ tubing. Hence, for redundancy, each Flux Loop tube has two wires that encirle 


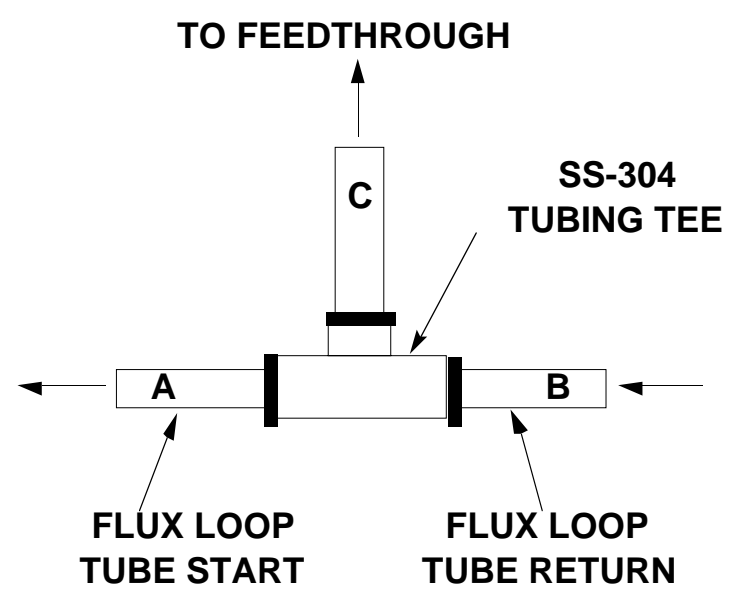

Fig.8. Partial schematic diagram of Flux Loop Tee-section which joins the ends of the flux loop and provides a conduit to the electrical feedthrough. The main toroidal tube (a and c) is $0.476 \mathrm{~cm}\left(3 / 16^{\prime \prime}\right)$ O.D. and the conduit to the feed through (c) is $0.635 \mathrm{~cm}(1 / 4 ") \mathrm{O}$. D. for the Passive Plate Flux Loops.

the torus and are individually connected to electrical feedthroughs. In the case of the Flux Loops mounted on the inside of the outer wall, the tubing outside diameter is $0.635 \mathrm{~cm}(0.25 ")$. The tubing for all of the other interior Flux Loops had a smaller outside diameter of $0.476 \mathrm{~cm}$ (0.188") due to space limitations. Standard 304-SS tubing Tees were used to join the ends of each Flux Loop C-section and provide an exit channel for the cabling to the electrical feedthroughs. The output of a particular Tee unit was coupled to either another 304-SS tube which served as a conduit for the exiting cable, or depending on accessibility, a $650{ }^{\circ} \mathrm{C}$ Markel Thermoflex-1200 fiberglass sleeving [9] was used.

\section{Electrical Feedthroughs}

The vessel internal hardware will be bakeable to $350{ }^{\circ} \mathrm{C}$. The outer vessel port covers will be cooled during bakeout to $150{ }^{\circ} \mathrm{C}$. The electrical feedthroughs must accommodate the $150{ }^{\circ} \mathrm{C}$ temperature of the port flange and any additional radiative heating from nearby hardware at a higher temperature. The feedthroughs used for the Center Stack sensors are standard 19 pin double ended Ceramaseal [13] connectors for the $\mathrm{Cu}-\mathrm{Cu}$ cables, or 10 pin thermocouple double ended connectors as required. The feedthroughs used for the outer vessel sensors are standard 32 pin double ended Ceramaseal [13] connectors for the $\mathrm{Cu}$ $\mathrm{Cu}$ cables, or 20 pin thermocouple double ended connectors as required. The cables are stressed relieved at the Center Stack feedthroughs by enclosing the cables in a sleeving fabricated from Nextel-312 [7] and fastened with ceramic thread [11]. The cables are stress relieved at the outer vessel feedthroughs using ceramic thread to fasten the cables to a
304-SS rod protruding into the vessel from the inside face of the port flange near the feedthrough.

\section{Conclusions}

The design of the more than 300 in-vessel sensor systems for the National Spherical Torus Experiment (NSTX) has encountered several challenging fusion reactor diagnostic issues involving high temperatures and space constraints. This has resulted in unique miniature, high temperature invessel sensor systems mounted in small spaces behind plasma facing armor tiles, and they are prototypical of possible high power reactor first-wall applications.

\section{Acknowledgments}

We acknowledge the technical contributions of $\mathrm{M}$. Anderson, J. Bartzak, W. Derry, S. Edwards, G. Gibilisco, K. Gilton, S. Jurcznski, P. Kivler, R. Knolls, G. Rossi, F. Simmons Jr., S. Vinson, and J. Winston. Work Supported by USDOE Contract No. DE-AC02-76-CHO3073

\section{References}

1. S. M. Kaye et al., "Physics Design of the national Spherical Torus Experiment", Fus. Technol. 36(1), 16 (1999).

2. Thermo Electric Co., 100 North Fifth Street, Saddle Brook, NJ, USA.

3. Carborundum Co., Boron Nitride Division, Audubon Industrial Park, Amherst NY 14228-2027, USA.

4. Ceramawire, P.O. Box 2597, Elizabeth City, NC 279082597, USA.

5. Airex Corp., Route 108, Dover, NH 03820, USA.

6. MACOR, Corning Materials Business, Corning Glass

Works, Corning, NY, 14830, USA.

7. OMEGA Engineering Corp., One Omega Drive, P. O. Box 4047, Stamford, CT 06907-0047, USA.

8. Nextel (Trade Mark, 3M Co.) Fiber Materiaals, Inc. 5 Morin Street, Biddeford, ME 04005-4497, USA.

9. Markel Corp. P.O. Box 752, Norristown, PA, USA. 10. Fortafix Inc. First Drove, Fengate, Peterborough, PE1 5 BJ, England.

11. Cotronics Corp., 3379 Shore Parkway, Brooklyn, NY, 11235, USA. \#391T-10 ceramic thread

12. B. McCormack, et al., "Rogowski Loop Designs for NSTX", in these Proceedings.

13. Cermaseal, Inc., P.O. Box 260, Route 20, New

Lebanon, NY 1215, USA. 